\title{
Regional Strategic Planning of hunting Nature Management: Political and Legal Aspects of Ensuring Sustainable Development
}

\author{
Ivan Grebnev*
}

\author{
Vyatka State University, Kirov, Russia \\ Vyatka State Agrotechnological University, Kirov, Russia \\ *Corresponding author. Email: ia_grebnev@vyatsu.ru
}

\begin{abstract}
Hunting nature management traditionally has an important place in the life of society as it performs various functions that help to solve a whole range of environmental, economic and social tasks and problems. Today, ensuring sustainability in the field of hunting and conservation of hunting resources is a strategic environmental priority implemented through the legal policy of state and legal regulators. An analysis of the federal faunal legislation and requirements for subnational acts of strategic planning of hunting nature management points out a number of significant substantive and procedural problems. The author finds it necessary to define and legalize the priority type of hunting activities in the Russian Federation, to improve the legislation, in particular, to make public discussions and professional examination of territorial hunting management schemes mandatory. The author concludes that the system of territorial hunting management planning in the Russian Federation is incomplete in both spatial and temporal aspects. He summarizes that the elimination of the identified defects is a prerequisite for ensuring the sustainable development of hunting nature management.
\end{abstract}

Keywords: Hunting, hunting industry, sustainability, strategic planning.

\section{INTRODUCTION}

Sustainable development today is a strategic priority and a criterion for the success of developing territories and individual spheres of activity, the most important factor in ensuring socio-economic well-being, environmental safety and the quality of life of the population. One of the main directions of Russia's transition to sustainable development is the creation of an appropriate legal framework that meets the needs of a balanced combination of environmental, economic and social interests of individuals, society and the state. In the system of legal acts, a special place is occupied by acts of strategic planning. It reflects the essence and characteristics of the state itself, determines directions of modernization of economic sectors and ideological and organizational foundations of public administration spheres. Based on the analysis of the current situation, values, expectations and needs of various social groups, these documents are designed to formulate state policy in a particular area of life, to form strategies for solving current and future tasks. Through the adoption of political and legal acts by the state, the systematic and complex impact on regulated public relations is increased.

In accordance with Article 72 of the Constitution of Russia, nature management, environmental protection and environmental safety are the subject of joint jurisdiction of the Russian Federation and its constituent entities. The concept of the transition of the Russian Federation to sustainable development, approved by Decree of the President of the Russian Federation from 01.04.1996 No. 440, states that the transition to sustainable development of the Russian Federation is possible only if sustainable development of all its regions is ensured, including rationalization of using natural potential. Thus, regional policies, including those for natural resource sectors, play an extremely important role in the transition to sustainable development.

The purpose of this study is to analyze problems of regional strategic planning of hunting nature management that hinder sustainability and ensure 
environmental safety, and to develop practical proposals for improving public administration in the sphere of public relations.

\section{MATERIALS AND METHODS}

The materials of the study are a set of provisions of the Federal Law from June 28, 2014 No. 172-FZ "On Strategic Planning in the Russian Federation", the procedure for drawing up a scheme for the placement, use and protection of hunting grounds on the territory of a constituent entity of the Russian Federation, requirements for its composition and structure, approved by the order of the Ministry of Natural Resources and Ecology of the Russian Federation from 31.08.2010 No. 335 , federal and regional regulations in the field of hunting and conservation of hunting resources, references.

The work has been carried out on the basis of a systematic approach using general scientific methods (dialectical method, method of comparative and systemic analysis, methods of generalization, classification and analogy) and special research methods (formal legal, comparative legal, technical legal, legal modeling).

\section{RESULTS AND DISCUSSION}

Federal Law from 24.07.2009 No. 209-FZ "On hunting and on preservation of hunting resources and on amending certain legislative acts of the Russian Federation (hereinafter - FZ No. 209) provides that the organization of protecting and using hunting resources and grounds at the regional level is carried out in accordance with the document of the territorial hunting management - the scheme of placing, using and protecting hunting grounds on the territory of the constituent entity of the Russian Federation (hereinafter also referred to as the Scheme). The composition, structure and procedure for drawing up the Scheme are approved by the Order of the Ministry of Natural Resources and Environment of the Russian Federation No. 335 from 31.08.2010 (hereinafter - Order No. 335). The scheme includes information on the goals of planning in the field of hunting and conservation of hunting resources, physical and geographical description of the territory, socio-economic characteristics, characteristics of the location and state of using hunting grounds and other territories, characteristics of the state of the number, location and use of hunting resources, measures to organize rational use of hunting grounds and hunting resources in the constituent entity of the Russian Federation. The Scheme is a document of regional strategic planning in the field of hunting and conservation of hunting resources. This document, on the basis of territorial features, is intended to form a regional economic mechanism for hunting nature management, ensuring the sustainable existence and use of the faunistic component of biodiversity. However, the substantive and regulatory analysis of requirements for drawing up the Scheme contained in Order No. 335 shows that the provisions of this regulatory legal act do not fully comply with the norms of Federal Law No. 172-FZ from 28.06.2014 "On Strategic Planning in the Russian Federation" (hereinafter - FZ № 172). The presence of the identified inconsistencies, coupled with the existing flaws in the federal hunting policy and legal regulators, leads to adopting substantively defective documents by the constituent entities of the Russian Federation. It creates risks for sustainable hunting wildlife management and ensuring environmental safety at the subnational level.

An important feature of the public administration system in this area is the excessive centralization of public powers [1]. An analysis of articles $32-34$ of Federal Law No. 209 shows that the most important decisions that determine the state and development of industry are developed and adopted at the federal level. The state bodies of the constituent entities of the Russian Federation have only insignificant possibilities to adapt federal rules of hunting use to the conditions of the respective territory. The situation is aggravated by the fact that state bodies of the Russian Federation have not yet approved a number of subordinate legal acts envisaged by the Federal Law No. 209 from July 24, 2009 (including standards for biotechnical measures in hunting grounds, methods of accounting for the number of species and group types of hunting resources, the procedure for creating zones to protect hunting resources, etc.). This circumstance negatively affects the structure and content of regional Schemes, the corresponding sections of which may contain only recommendatory provisions. The non-binding nature of the latter forms wide legal gaps and determines the presence of a complex of risks and threats in the system of hunting nature management.

Federal Law No. 172 points out the principle of balancing the strategic planning system among the principles of strategic planning. This principle means that strategic planning documents must be coordinated and balanced in terms of priorities, goals, objectives, activities, indicators and implementation deadlines. However, according to [2, 3], the key and qualitative drawback of Russian political and legal acts in the field of hunting and conservation of hunting resources is their conceptual uncertainty, lack of priorities and, as a consequence, the presence of mutually exclusive tasks of sectoral development. Until now, the priority type of hunting activity has not been defined and formally fixed. That is, no choice has been made between the elite model of hunting, when hunting is the privilege of 
wealthy citizens, and the egalitarian model, when the right to hunt does not depend on the property status of citizens [4]. The lack of conceptual certainty in documents at the national level is reproduced at the subnational level, hindering the formation of an effective and balanced policy and legislation for the protection and rational use of hunting resources. Note that in foreign scientific publications considerable attention is paid to strategies for protecting and using resources of hunting animals $[5,6,7]$, and to questions about the meaning and functions of hunting nature management in modern society. [8, 9].

The overwhelming majority of documents of the territorial hunting management of the constituent entities of the Russian Federation do not provide mechanisms for implementing tasks of the development of hunting and hunting economy and adaptive management. The measures envisaged by the Schemes only express the need to achieve certain results, without information on the timing, stages, tools, indicators, participants in the solution of the corresponding tasks, and sometimes also on the objects of influence. There is no description of alternative options for achieving the tasks set, the possibility of changing the parameters of the regulatory action depending on the changed conditions or parameters of the target. For example, the Scheme for placing, using and protecting hunting grounds on the territory of the Altai Territory, approved by the decree of the Governor of the Altai Territory No. 15 from February 4, 2019, includes the direction for developing the hunting economy of the region "Intensification of fishing and procurement of furbearing species of animals and other raw materials of animal origin" ... It is declared that the implementation of this direction is possible by increasing purchase prices, attracting an additional contingent of hunters, canceling fees and "licensing their production by piece", as well as holding regional fairs or auctions. However, within the framework of this direction, there are no planning elements, implementation mechanisms, an assessment of their interdependence, possibility of correcting regulatory efforts within the framework of this direction. Such defects are typical for Hunting Planning Schemes and require appropriate correction.

Federal Law No. 172 establishes the need for public discussion of draft strategic planning documents. The scientific literature widely discusses the importance of this tool, its role in consolidating and mobilizing the population, identifying and harmonizing interests of various social groups [10-12]. However, the procedure for the adoption of regional Schemes does not provide the procedure for their public discussion, not complying in this part with the requirements of federal legislation. According to the author, types, forms, timing, methods, objects and tools of hunting nature management should be acceptable to the local community and be combined with other nature management in this location. Thus, holding a public discussion of the projected decisions is an important mechanism for informing citizens about the established parameters for the protection and use of hunting resources in a particular area, taking into account their interests, strengthening confidence in public authorities and supporting documents of territorial development adopted by them. Along with holding a public discussion, we consider it expedient to conduct an independent professional examination of the projects of the developed Schemes. The involvement of a wide range of specialists, including researchers and practitioners, will make it possible to better, objectively and comprehensively determine the long-term goals, objectives, resources, mechanisms, terms and indicators for developing hunting and hunting economy in the corresponding constituent entity of the Russian Federation, harmonize them with social and economic development of the region and other sectoral documents of territorial planning, to avoid possible management decisions on an emotional basis.

Russian territorial hunting management planning is incomplete in both spatial and temporal aspects. Federal Law No. 209 provides the availability of hunting management documents exclusively at the subnational level. However, the areas of populations of many species do not coincide with the administrative boundaries of the constituent entities of the Russian Federation [13]. In this connection, the management of populations of hunting animals, activities to ensure sustainability in the hunting sector should have a coordinated interregional character. This requires the development and approval of higher-level Schemes interregional and (or) federal. In our opinion, the validity period of such documents should be increased to 50 years, which is necessary for formulating and implementing long-term objectives of industry development. It will take into account the changing configuration of hunting grounds leased to legal entities and individual entrepreneurs for a period of 20 to 49 years.

\section{CONCLUSIONS}

Thus, the layout, use and protection of hunting grounds on the territory of a constituent entity of the Russian Federation is a document of regional strategic planning. This act is intended to determine the priorities and content of the state hunting management policy at the subnational level, targets and the desired state of the region's hunting economy in the medium term. On its basis, correcting and improving legislation in the field of hunting nature management should be carried out. However, the analysis of the requirements for the content of the document, the procedure for its adoption shows that these provisions, coupled with the presence of a number of significant defects in the federal hunting policy and legal regulators, determine the adoption of 
formal documents by the constituent entities of the Russian Federation, the actual content of which does not form a full-fledged conceptual and legal basis of public administration in the considered area. This circumstance poses a threat to sustainable hunting wildlife management and environmental safety at the subnational level.

\section{REFERENCES}

[1] M.N. Andreev, N.V. Kraev, V.N. Kraeva, Regional and state policy in the sphere of hunting and hunting farm, Ecological law (4) (2013) pp. 17-23.

[2] M.N. Andreev, N.V. Kraev, V.N. Kraeva, State policy in the field of hunting and game management: history and modern practice, Prof. B.M. Zhitkov Russian Research Institute of Game Management and Fur Farming of Russian Academy of Agricultural Sciences, 2013.

[3] I. Grebnev, Problems of political and legal support for sustainable development of the hunting industry in Russia, in: First Conference on Sustainable Development: Industrial Future of Territories (IFT 2020), vol. 208, E3S Web of Conferences, 2020. DOI:

https://doi.org/10.1051/e3sconf/202020806008.

[4] S.P. Matveychuk, Elitism and egalitarianism in Russian hunting, in: Modern problems of nature management, hunting and fur farming, Prof. B.M. Zhitkov Russian Research Institute of Game Management and Fur Farming of Russian Academy of Agricultural Sciences, 2007, pp. 271273.

[5] M. Nie, State Wildlife Policy and Management: The Scope and Bias of Political Conflict, vol. 64, Issue 2, Public Administration Review, 2004, pp. 221-233. DOI: https://doi.org/10.1111/j.15406210.2004.00363.x.

[6] P.T. Fell, Conflict and legitimacy: explaining tensions in Swedish hunting policy at the local level, vol. 17, issue 1, Environmental Politics, 2008, pp. 105-114. DOI: https://doi.org/10.1080/09644010701811707.

[7] J. Hiedanpää, D.W. Bromley, The harmonization game: Reasons and rules in European biodiversity policy, vol. 21, issue 2, Environmental Policy and Governance, 2011, pp. 99-111. DOI: https://doi.org/10.1002/eet.561.

[8] C.A. Jacobson, D.J. Decker, Governance of state wildlife management: reform and revive or resist and retrench?, vol. 21, No. 5, Society and Natural Resources, 2008, pp. 441-448. DOI: https://doi.org/10.1080/08941920801898465.
[9] A. Fischer, C. Sandström, M. Delibes, et al., On the multifunctionality of hunting - an institutional analysis of eight cases from Europe and Africa, vol. 56, issue 4, Journal of Environmental Planning and Management, pp. 531-552. DOI: https://doi.org/10.1080/09640568.2012.689615.

[10] K.S. Afanasyev, Problems of optimization of the strategic planning system at the municipal level, vol. 3, Economy of the new world, 2016

[11] Ch. Dobson, The citizen's handbook. A guide to building community, Vancouver citizen's committee, 2011.

[12] E. Lozano, Density in communities, or the most important factor in building urbanity, in: Larice M., Macdonald E. (eds), Urban design reader, Second edition, London; New York: Routledge, 2013, pp. 399-414.

DOI: https://doi.org/10.4324/9780203094235.

[13] G.N. Ogureeva, T.V. Kotova, Map "Biomes of Russia" and its role in improving environmental education and conservation, vol. 1, no. 20, Materials of the International Conference "InterCarto / InterGIS", 2016, pp. 632-641. 